\title{
Pulsed-field gel electrophoresis profile homogeneity of Mycobacterium avium subsp. paratuberculosis isolates from cattle and heterogeneity of those from sheep and goats Iker Sevilla, Joseba M Garrido, Marivi Geijo and Ramon A Juste*
}

Address: Instituto Vasco de Investigación y Desarrollo Agrario (NEIKER), Berreaga, 1, 48160 Derio, Bizkaia, Spain

Email: Iker Sevilla - isevilla@neiker.net; Joseba M Garrido - jgarrido@neiker.net; Marivi Geijo - mgeijo@neiker.net; Ramon A Juste* - rjuste@neiker.net

* Corresponding author

Published: 12 March 2007

BMC Microbiology 2007, 7:18 doi:10.1| 86/|47|-2/80-7-18
Received: I October 2006

Accepted: 12 March 2007

This article is available from: http://www.biomedcentral.com/I47I-2/80/7//8

(C) 2007 Sevilla et al; licensee BioMed Central Ltd.

This is an Open Access article distributed under the terms of the Creative Commons Attribution License (http://creativecommons.org/licenses/by/2.0), which permits unrestricted use, distribution, and reproduction in any medium, provided the original work is properly cited.

\begin{abstract}
Background: Mycobacterium avium subsp. paratuberculosis (Map) causes paratuberculosis in animals and is suspected of causing Crohn's Disease in humans. Characterization of strains led to classify paratuberculosis isolates in two main types, cattle type strains, found affecting all host species, and sheep type strains, reported affecting mainly sheep. In order to get a better understanding of the epidemiology of paratuberculosis a large set of Map isolates obtained from different species over the last 25 years have been characterized. Five-hundred and twenty isolates from different hosts (cattle, sheep, goats, bison, deer and wild boar) and origins had been cultured and typed by IS/3 I / restriction-endonuclease-analysis. Two-hundred and sixty-nine isolates were further characterized by pulsed-field gel electrophoresis (PFGE) using SnaBI and Spel endonucleases. Differences in strain isolation upon various media conditions were also studied.
\end{abstract}

Results: All bovines, 4 and $26 \%$ of Spanish sheep and goats, respectively, and the deer and wild boar studied, carried IS I I I I-Cattle type strains. IS / 3 I I-Sheep type encompassed $96 \%$ and $74 \%$ of Spanish sheep and goats, and all three Portuguese sheep. Thirty-seven distinct multiplex PFGE profiles were found, giving 32 novel profiles. Profiles $2-I$ and I-I accounted for the $85 \%$ of cattle isolates. Ten distinct profiles were detected in Spanish sheep, none of them with an incidence higher than 25\%. Profile 16-II (43\%) and another three profiles were identified in Spanish caprine cultures. The hierarchical analysis, clustered all profiles found in cattle, "wild" hosts and some small ruminants within the same group. The other group included II profiles only found in Spanish sheep and goats, including Spanish pigmented profiles. Differences in growth requirements associated with isolate genotype were observed.

Conclusion: Cattle in Spain are infected with cattle type strains, while sheep and goats are mainly infected with sheep type strains. Although 7H9 broth based culture media seem to broadly cover the growth requirements of most Map strains, the use of various solid media is recommended to reduce any recovery biases. High genetic homogeneity of isolates from cattle, and heterogeneity of those from sheep and goats have been detected. 


\section{Background}

Mycobacterium avium subsp. paratuberculosis (Map) is an obligate pathogen causing paratuberculosis in ruminants and other animal species, and suspected of being responsible for Crohn's Disease in humans. Paratuberculosis causes significant economic losses to farmers and is becoming prevalent among livestock populations worldwide [1]. Strategies for paratuberculosis prevention and control require an understanding of the epidemiology of the disease. In particular, strain genotyping is a valuable tool for epidemiological tracing of pathogenic microorganisms.

Map isolates are generally identified by acid fast staining, the size of the bacilli, extremely slow growth, dependence on mycobactin, and the presence of several copies of the IS900 element in its genome. However, the description of some Map strains that are not dependent on mycobactin $[2,3]$ and the presence of IS900-like insertion sequences in bacteria other than Map [3-6] mean that more reliable methods of characterization would be valuable. The most commonly used typing method is the analysis of restriction fragment length polymorphism using IS900 specific probes (IS900-RFLP). IS900-RFLP classified isolates from cattle, sheep and goats into two major groups using BstEII endonuclease [7]. These were called sheep $(S)$ and cattle (C) types because of their apparent predominance in those host species. An intermediate (I) group was also detected in two sheep from Canada. Strains from sheep are difficult to culture $[8,9]$, making further strain classification difficult. BstEII-C or cattle types have been described in cattle from New Zealand, Australia, the USA, Denmark, the Czech Republic, Slovakia, Hungary, Germany, France, Morocco, the United Kingdom, Austria, Italy, the Netherlands, Slovenia, Spain, Sweden, Argentina and Norway [7,10-19]. These RFLP types have also been found infecting sheep from Canada, the USA, the Czech Republic, France, Greece, Australia, Spain and the United Kingdom [7,15-18], and goats from New Zealand, Norway, Argentina, Germany, Denmark, Italy, the United Kingdom, Australia and the USA [7,10-12,16-18]. These strains have also been found in cervids from New Zealand, the Czech Republic, the United Kingdom and Argentina [14,16,20-22], in lagomorphs from Scotland and the Czech Republic $[13,21]$, in alpaca and rhinoceros from Australia [11] and in Czech moufflon and wild boar [21]. In contrast, the literature contains little evidence of BstEII$S$ strains and BstEII-I strains being as distributed in animal species: they have been reported in sheep from Canada, New Zealand, the Faroe Islands, South Africa, Morocco and Australia $[7,10,11,17,19,23,24]$, in goats from New Zealand and the Czech Republic $[7,15]$, cattle from the Czech Republic [15], and deer from New Zealand and the Czech Republic [20,21]. IS1311 PCR-restriction endonuclease analysis (REA) [25] led to the identification of $S$ strains in Australian and Icelandic sheep and cattle [26] and Spanish sheep and goats [27]. A recent study based on IS1311 PCR-REA and other two PCR methods reported infection of Spanish goats and bullfighting cattle with $S$ (Type I/III) strains [28].

Another promising technique for typing this parasitic bacterium is pulsed-field gel electrophoresis of digested genomic DNA (PFGE). It has been useful for typing other important mycobacteria including M. avium and M. tuberculosis [29-33]. Pigmented and non-pigmented isolates from a wide variety of hosts and origins were analyzed by SnaBI-SpeI PFGE in an effort to standardize the technique for paratuberculosis strain typing [34]. Subsequently, caprine isolates from Spain, Scotland and Norway were analyzed [35]. Thus, 26 multiplex profiles have been described and clustered into 3 major types. Other genotyping techniques have been investigated in an attempt to improve upon the discriminatory power of RFLP and PFGE [36-40]. However, some of them do not provide enough additional information and others need to be validated with larger numbers of strains already characterized by RFLP and/or PFGE and from diverse host and geographic origins to assess their value for further epidemiological studies on paratuberculosis.

There have been few studies reporting molecular characterization of Spanish paratuberculosis isolates [27,28,35]. Our aim in this work was to characterize by IS1311 PCRREA and PFGE typing a large set of Map isolates obtained at Neiker from different species over the last 25 years to serve as a basis for a better understanding of the epidemiology of paratuberculosis.

\section{Results}

All bovine isolates grew in 2-4 months on HEY, and some cultured after 2002 also grew on LJ or in 7H11 with mycobactin J. Ovine isolates grew in 3-7 months on LJ, 7H11 (with or without mycobactin J) and/or 7H9 (with or without mycobactin J), but only from tissue samples. None of the ovine samples used to inoculate HEY produced Map colonies. Goat isolates grew in 2-7 months on the same media as sheep isolates, and some of them were also successfully isolated on HEY. Mycobacterial cells were not successfully propagated from several cases in small ruminants, although the presence of Map was identified on the basis of acid fastness, IS900 and locus 251 PCR results, and IS1311 PCR-REA result. Indian isolates grew in 2-4 months on HEY with no added pyruvate. Deer isolates grew in 3 months on HEY and LJ, and wild boar isolates grew in 2-3 months on HEY and 7H11 with mycobactin J. The isolation media for cultures typed by PFGE are given in Table 1. Subcultures in liquid medium of $C$ and $B$ strains grew faster than those of $S$ strains (data not shown). 
Table I: SnaBI-Spel PFGE classification of Map strains.

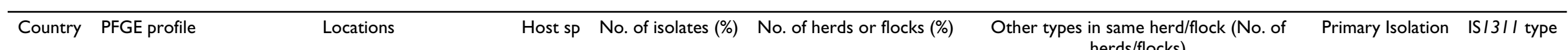

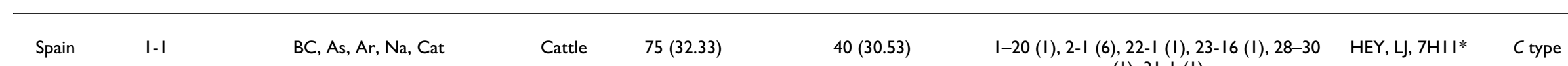

Cattle I (0.43)

(I), $31-1$ (I)

\begin{tabular}{|c|c|}
\hline$* 1-10$ & $\mathrm{BC}$ \\
\hline$* I-20$ & $\mathrm{Na}$ \\
\hline$* 1-27$ & $\mathrm{BC}$ \\
\hline $2-1$ & BC, As, Can, Ga, CL, Ar, N \\
\hline $2-5$ & As \\
\hline $2-10$ & Can, CL, Ex \\
\hline$* 2-12$ & $\mathrm{BC}$ \\
\hline$* 2-14$ & $\mathrm{Ga}$ \\
\hline$* 2-15$ & $\mathrm{BC}, \mathrm{Ma}$ \\
\hline$* 2-25$ & $\mathrm{CL}$ \\
\hline$* 2-31$ & $\mathrm{CL}$ \\
\hline$* 20-27$ & $\mathrm{BC}$ \\
\hline$* 21-1$ & Can \\
\hline$* 22-1$ & $\mathrm{Ar}$ \\
\hline$* 23-16$ & $\mathrm{BC}$ \\
\hline$* 24-19$ & $\mathrm{Ma}$ \\
\hline$* 27-26$ & $\mathrm{BC}$ \\
\hline$* 28-30$ & $\mathrm{BC}$ \\
\hline$* 3 I-1$ & $\mathrm{Na}$ \\
\hline$* 32-1$ & $\mathrm{BC}, \mathrm{Na}$ \\
\hline$* 33-1$ & $\mathrm{BC}$ \\
\hline$* 40-1$ & $\mathrm{CL}$ \\
\hline
\end{tabular}

Cattle

$1(0.43)$

I (0.76)

Cattle

I (0.43)

I (0.76)

I-I (I), 3I-I (I)

I (0.76)

I2I (52.16)

76 (58.02)

I-I (6), 2-10 (2), 2-I5 (I), 2-3। (I), 22-I

(I), 23-16 (2), 28-30 (I)

I (0.76)

Cattle I (0.43)

3 (2.29)

2-I (2)

I (0.76)

Cattle I (0.43)

I (0.76)

3 (2.29)

I (0.76)

I (0.76)

2 (2.29)

I (0.76)

Cattle I (0.43)

I (0.76)

7 (5.34)

Cattle $\quad 7$ (3.02)

I (0.76)

I (0.76)

Cattle I (0.43)

I (0.76)

I (0.76)

2 (1.53)

I (0.76)

I (0.76)

$2-I(2)$
$2-I(I), 23-16(I)$
$2-I(I)$
I-I (I), 2-I (I)
I-I (I), 2-I (2), 2-I5 (I)
I-I (I), 2-I (I)
I-I (I), I-20 (I)


Table I: SnaBI-Spel PFGE classification of Map strains. (Continued)

\begin{tabular}{|c|c|c|c|c|c|c|c|c|}
\hline & $2-1$ & $\mathrm{Ar}$ & Sheep & I (5.88) & I (I0.0) & & LJ & C type \\
\hline & $* 25-23$ & $\mathrm{Ar}$ & Sheep & I (5.88) & I (I0.0) & & LJ & $S$ type \\
\hline & $* 26-24$ & $\mathrm{BC}, \mathrm{Na}$ & Sheep & $3(17.65)$ & $2(20.0)$ & & LJ, 7H9*+7HII & S type \\
\hline & $* 30-11$ & $\mathrm{BC}$ & Sheep & $2(11.76)$ & $2(20.0)$ & $39-17(2), 39-2 I(I), 4 I-32(I)$ & 7HII & $S$ type \\
\hline & $* 35-29$ & $B C$ & Sheep & I (5.88) & I (I0.0) & & $\begin{array}{c}\text { 7HII*, } \\
7 \mathrm{H} 9+7 \mathrm{HII}\end{array}$ & $S$ type \\
\hline & $* 36-18$ & $\mathrm{BC}$ & Sheep & I (5.88) & $\mathrm{I}(10.0)$ & $38-22(1), 39-17(1)$ & 7HII & $S$ type \\
\hline & $* 38-22$ & $\mathrm{BC}$ & Sheep & I (5.88) & I $(10.0)$ & $36-18(1), 39-17(1)$ & $7 \mathrm{HII}$ & $S$ type \\
\hline & $* 39-17$ & $\mathrm{BC}, \mathrm{Na}$ & Sheep & $4(23.53)$ & $4(40.0)$ & $\begin{array}{c}30-1 I(2), 36-18(I), 38-22(I), 39-2 I(I), \\
4 I-32(I)\end{array}$ & 7HII & $S$ type \\
\hline & $* 39-21$ & $\mathrm{BC}$ & Sheep & $2(11.76)$ & $2(20.0)$ & $30-11(1), 39-17(1)$ & $7 \mathrm{HII}$ & S type \\
\hline & $* 4 \mid-32$ & $\mathrm{BC}$ & Sheep & I (5.88) & I (I0.0) & $30-11$ (I), 39-17 (I) & $7 \mathrm{HII}$ & $S$ type \\
\hline & $2-1$ & $\mathrm{BC}$ & Goat & $2(28.57)$ & I (20.0) & & HEY, 7HII* & C type \\
\hline & $\mid 5-1$ & An & Goat & I (14.29) & I (20.0) & $34-28(I)$ & $\begin{array}{c}\text { 7HII*, } \\
\text { 7H9+7HII }\end{array}$ & C type \\
\hline & $16-11$ & $C L, A n, I B$ & Goat & $3(42.86)$ & $3(60.0)$ & & LJ, 7H9+7HII & $S$ type \\
\hline & $* 34-28$ & An & Goat & I (I4.29) & I (20.0) & $15-\mid(1)$ & $7 \mathrm{H} 9+7 \mathrm{HII}$ & $S$ type \\
\hline & $* 37-1$ & CM & Deer & $2(100.0)$ & I (I00.0) & & HEY & C type \\
\hline & $2-1$ & CM & $\begin{array}{l}\text { Wild } \\
\text { Boar }\end{array}$ & I $(100.0)$ & I $(100.0)$ & & HEY, 7HII* & C type \\
\hline \multirow[t]{2}{*}{ India } & $* 29-1$ & Mathura & Sheep & $2(100.0)$ & I (100.0) & & HEY & B type \\
\hline & $* 29-1$ & Farah & Goat & $5(100.0)$ & I (I00.0) & & HEY & B type \\
\hline USA & $2-1$ & Montana & Bison & $3(100.0)$ & I (100.0) & & LJ & B type \\
\hline
\end{tabular}

Details of SnaBI-Spel multiplex profiles of the 269 Map isolates studied by PFGE: geographic origin, number of isolates, number of herds/flocks of the indicated host species, primary isolation media and

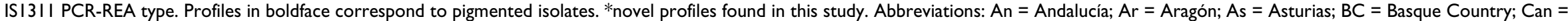
Cantabria; Cat = Cataluña; $C L=$ Castilla y León; $C M=$ Castilla-La Mancha; Ex = Extremadura; Ga = Galicia; IB = Balearic Islands; Ma = Madrid; Na = Navarra. HEY = Herrold's Egg Yolk Medium with mycobactin J; LI = Löwenstein-Jensen Medium with mycobactin J; 7HII = OADC supplemented Middlebrook 7HII Medium without mycobactin J; 7HII* = OADC supplemented Middlebrook 7HII Medium with mycobactin J; 7H9+7HII = OADC supplemented Middlebrook 7H9 Broth without mycobactin J, subcultured on 7HII; 7H9*+7HII = OADC supplemented Middlebrook 7H9 Broth with mycobactin J, subcultured on $7 \mathrm{HII}$. 


\section{IS900 PCR and Locus 25 I PCR}

PCR amplification detected both IS900 and Locus 251 in all 520 isolates used in the study. These findings and the phenotypic characteristics (see "materials and methods" section) allowed all bacterial isolates used to be identified as Map.

\section{ISI 3 I I PCR-REA}

The IS1311 insertion sequence was successfully amplified from all isolates. Restriction analysis of amplicons assigned each isolate to one of the 3 strain types previously described by this method. All bovine isolates, as well as the deer and wild boar isolates, exhibited band patterns corresponding to $C$ type strains (Table 2). In contrast, $96.3 \%$ and $73.7 \%$ of Spanish sheep and goats, respectively, gave isolates with banding patterns corresponding to the $S$ type strains; all sheep isolates from Portugal were also classified in this group. The other Spanish sheep (3.7\%) and goats $(26.3 \%)$ were infected by $C$ type strains. Interestingly, two goat flocks were infected by both types, some goats carrying a $C$ strain and others an $S$ strain. All isolates from Indian sheep and goats and from American bison were typed as $B$ strains.

\section{SnaBI-Spel PFGE analysis}

Restriction endonucleases SnaBI and SpeI differentiated 26 and 24 pulsotypes, respectively (Figures 1 and 2). Thus, a total of 37 different multiplex PFGE profiles were identified among the 269 Map isolates analyzed. Twenty-two of the patterns identified with SnaBI (20-41) and 19 of those obtained with SpeI (14-32) have not been described previously; the two endonucleases together giving 32 novel PFGE multiplex profiles in our collection of isolates (see Table 1 and Figure 3). Twenty-three different multiplex profiles were detected in Spanish cattle, 10 in Spanish sheep and 4 in Spanish goats. Profiles 2-1 and 1-1 included 52.16 and $32.33 \%$ of cattle isolates, found in 58.02 and $30.53 \%$ of herds analyzed, respectively. The calculated incidence for each of the other profiles identified in cattle was lower than 1\%, except for profile 23-16 which included 3\% of bovine isolates. In Spanish sheep, strain type 39-17 was the most frequently found with four isolates detected in $40 \%$ of ovine flocks. Four pigmented sheep isolates exhibited novel restriction patterns (26-24 and 25-23), and accounted for the $23.5 \%$ of sheep isolates. The other types observed in Spanish sheep appeared only once or twice. Profile 16-11 was found in three goats, and profiles 2-1, 15-1 and 34-28 were identified in a single animal each. The two isolates from deer had profile $37-1$, and the wild boar isolate was typed as 2-1. All the Indian isolates gave the same multiplex profile regardless of their host species. All bison isolates from USA were 2-1.

Several herds/flocks carried strains of different profiles: up to 3 in 3 bovine herds and 3 sheep flocks (34 bovine herds, 4 sheep flocks and 1 goat flocks gave more than one isolate). Eleven bovine and one goat herds gave isolates with two different profiles. The other flocks/herds each gave isolates with a single multiplex pattern within the same herd/flock. PFGE typing results according to host species breeds are reported in Table 3.

In five cases, more than one isolate cultured from the same animal was available. Two cows, one goat and one

Table 2: IS I3 I I classification of Map strains.

\begin{tabular}{|c|c|c|c|c|c|c|}
\hline Geographic origin & & Host sp. & no. of isolates & no. of animals(\%) & no. of herds/flocks(\%) & ISI3II type \\
\hline \multirow[t]{7}{*}{ Spain } & $\begin{array}{c}\text { - } \mathrm{Ar}(19), \mathrm{As}(9), \mathrm{BC}(228), \mathrm{Can}(22) \\
\mathrm{CL} \text { (92), CM (2), Cat (9), Ex (1), Ga } \\
\text { (13), Ma (4), Na (46) }\end{array}$ & Cattle & 444 & $409(100.0)$ & $178(100.0)$ & $C$ \\
\hline & $\cdot \mathrm{Ar}$ & Sheep & 1 & I (3.7) & I (6.67) & $C$ \\
\hline & - An (I), Ar (2), BC (I7), Na (5) & Sheep & 26 & $26(96.3)$ & $14(93.33)$ & $S$ \\
\hline & - An (4), BC (3; I goat) & Goat & 7 & $5(26.32)$ & $4(36.36)$ & $C$ \\
\hline & - An (II), CL (I), Ga (I), IB (I) & Goat & 14 & $14(73.68)$ & $9(81.82)$ & $S$ \\
\hline & $\cdot \mathrm{CM}$ & Deer & 2 & $2(100.0)$ & I (100.0) & $C$ \\
\hline & $\cdot \mathrm{CM}$ & Wild boar & I & $\mathrm{I}(100.0)$ & I (100.0) & $C$ \\
\hline Argentina & -- & Cattle & 8 & $8(100.0)$ & - & $C$ \\
\hline France & $\cdot$ Lys & Cattle & 1 & $\mathrm{I}(100.0)$ & I (100.0) & $C$ \\
\hline Portugal & - Trás-os-Montes & Sheep & 3 & $3(100.0)$ & $2(100.0)$ & $S$ \\
\hline \multirow[t]{2}{*}{ India } & - Mathura & Sheep & 2 & $2(100.0)$ & I (100.0) & $B$ \\
\hline & - Farah & Goat & 8 & $8(100.0)$ & I (100.0) & $B$ \\
\hline \multirow[t]{2}{*}{ USA } & - Montana & Bison & 3 & $3(100.0)$ & I (100.0) & B \\
\hline & & Total & 520 & 483 & & \\
\hline
\end{tabular}

The 520 Map isolates from different host species classified as C (cattle), S (sheep) or B (bison) type according to ISI3II PCR-REA. Numbers of

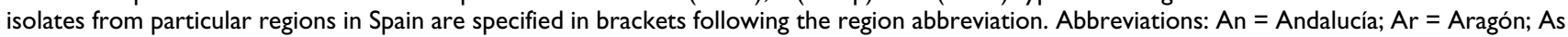
$=$ Asturias; $\mathrm{BC}=$ Basque Country; Can = Cantabria; Cat = Cataluña; $\mathrm{CL}=$ Castilla y León; $\mathrm{CM}=$ Castilla-La Mancha; Ex = Extremadura; Ga = Galicia; IB = Balearic Islands; $\mathrm{Ma}=$ Madrid; $\mathrm{Na}=$ Navarra. 


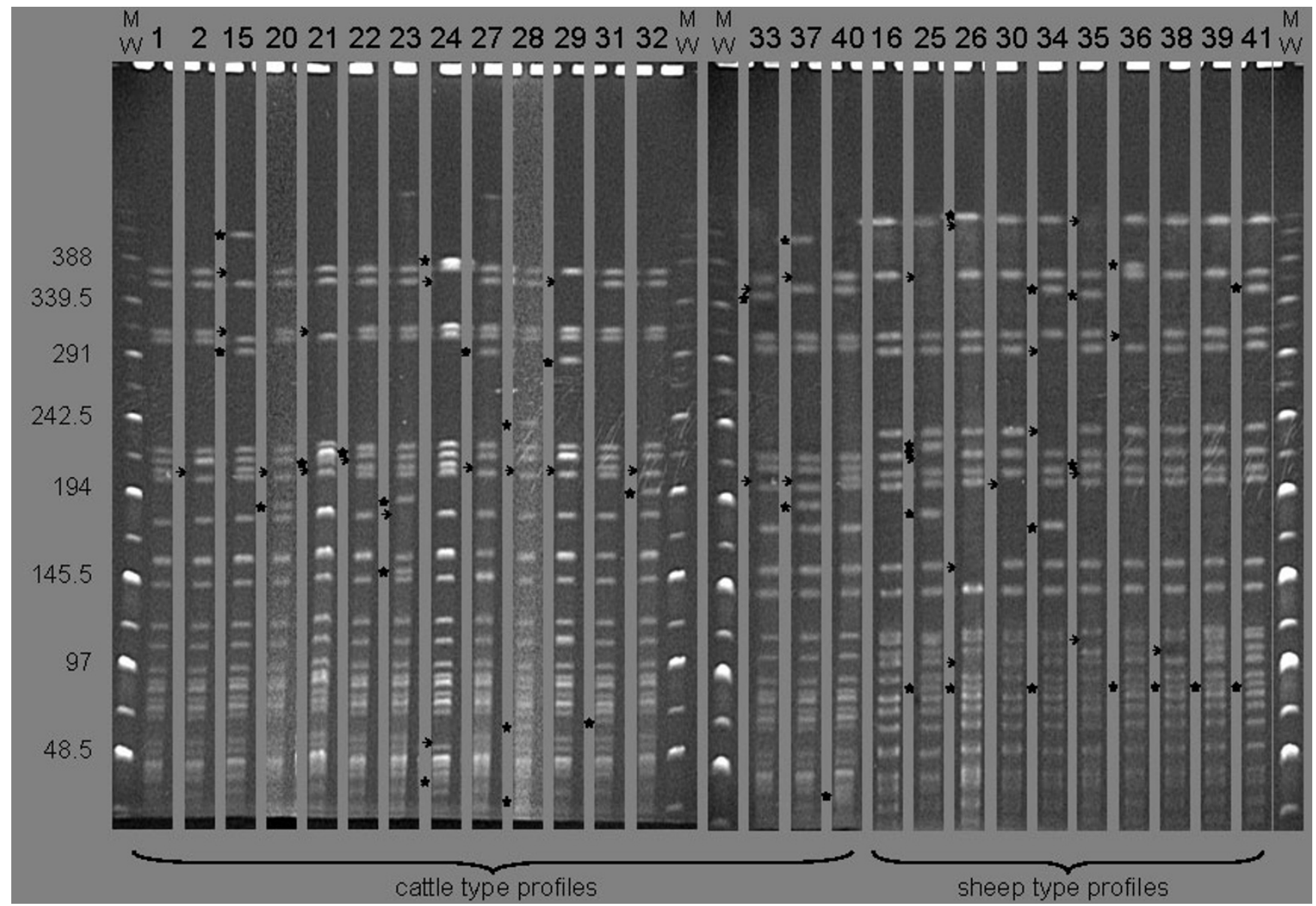

Figure I

SnaBI restriction profiles. Photographs of two gels comprising the 26 different SnaBI pulsotypes detected. Numbers above the lanes correspond to the PFGE nomenclature. Arrows and asterisks indicate differences (band loss and new band, respectively) between type I and cattle type profiles, and between type 16 and sheep type profiles. $M W=$ molecular weight standards, in Kilobases (Kb).

deer yielded two isolates each one but the restriction patterns of isolates from the same animal were identical. In contrast, an isolate cultured in 2002 from the feces of one Holstein bull was of 1-1 type, whereas the two isolates cultured in 2003 from the small intestine and mesenteric lymph nodes of the same animal, were of 2-1 and 28-30 profiles, respectively.

\section{Phylogenetic analysis of PFGE profiles and estimation of genetic diversity}

Phylogenetic analysis of the multiplex profiles obtained produced a dendrogram with two main branches (Figure 3 ). One includes all profiles found in cattle, deer, wild boar, Indian small ruminants and American bison, for a total of 26 profiles. Previously described profiles 1-1, 2-1, $2-5,2-10$ and 15-1, were part of this group. The other main branch includes 11 profiles only found in sheep and goats from Spain, including the 16-11 profile identified previously and both profiles detected in pigmented isolates (25-23 and 26-24). The discriminatory power for this PFGE strain typing method calculated as Simpson's Index of Diversity, taking into account all isolates and profiles described, was 0.693 . The index value was 0.621 for Spanish cattle, and 0.666 for Spanish goats, but much higher, 0.865 , for Spanish sheep.

\section{Discussion}

Differences in the success of Map isolation and, more specifically, difficulties in culturing this micro-organism from ovine specimens, have been repeatedly reported in many countries (reviewed in reference [9]). Some authors suggest that different host species preferentially carry different strains, and the differing cultivation requirements of these strains causes the divergent efficacy of isolating the organism $[2,7,10,41]$. In contrast, other researchers did not report any links between host species, strain type and/ 


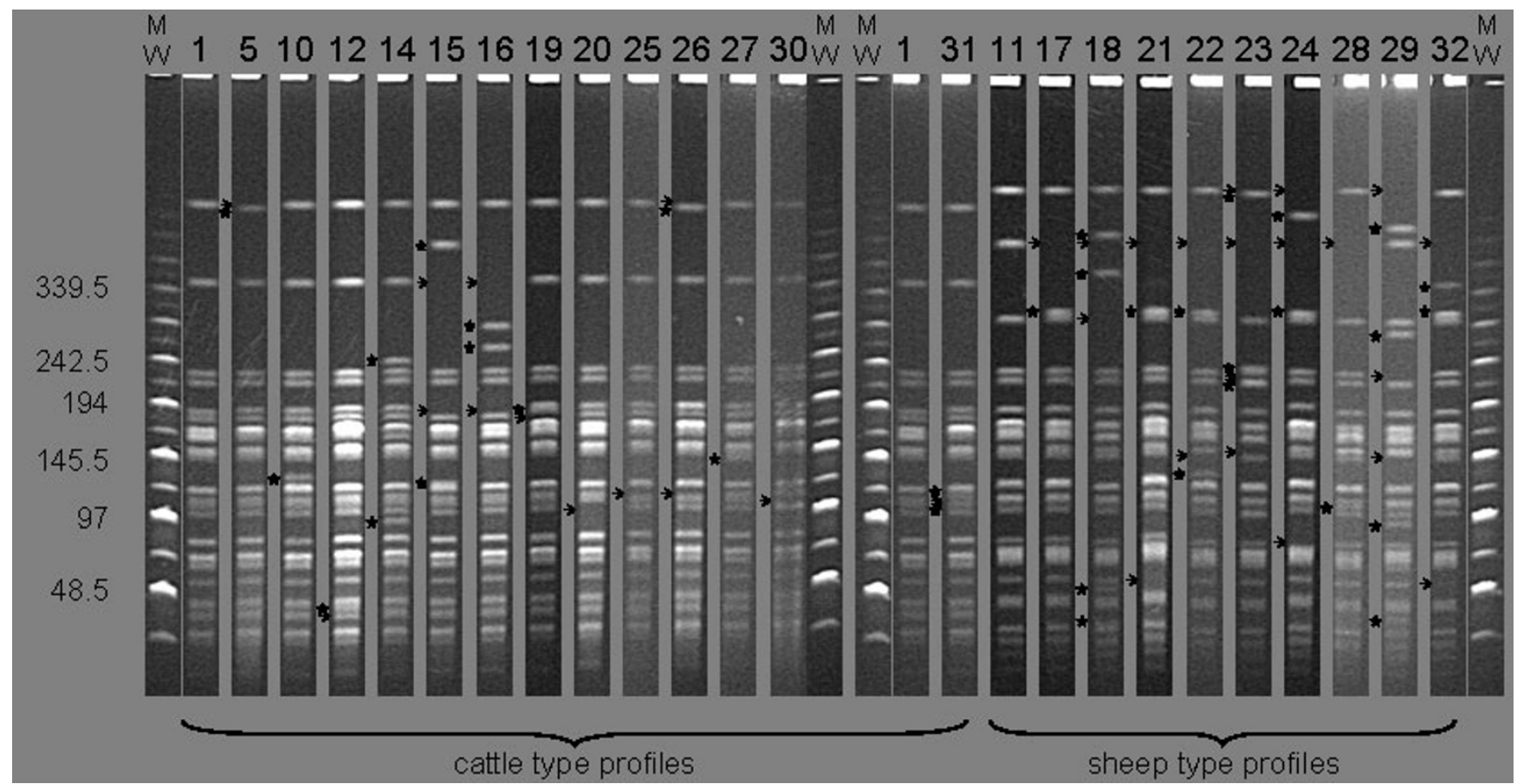

Figure 2

Spel restriction profiles. Photographs of two gels comprising the 24 different Spel pulsotypes detected. Numbers above the lanes correspond to the PFGE nomenclature. Arrows and asterisks indicate differences (band loss and new band, respectively) between type I and cattle type profiles, and between type II and sheep type profiles. MW = molecular weight standards, in Kilobases (Kb).

or culture characteristics $[16,17,34]$. Our study does not resolve this issue because we did not use the same methods for all cultures, and culture attempts were carried out with the concrete objective of isolating Map from paratuberculosis-affected animal specimens received. Nevertheless, our results are consistent with other reports on the comparison of different media for Map culture [9,42], and confirm the existence of different culture requirements according to Map type. IS1311 PCR-REA typing with our collection of bovine isolates - presumably the least biased due to its size and to the use of various culture media confirms the finding of a previous study [27]: Holstein, Limousin and Pyrenean cattle in Spain are infected with $C$ type strains. These strains are more easily isolated on HEY than on other solid media. This strain type was found only in one of 27 isolates from Spanish sheep, the others, like those from Portugal $(n=3)$ being $S$ type. This indicates that sheep in Spain and probably also in Portugal are mostly infected with $S$ strains. Some of these were isolated with ease on 7H11 without mycobactin J, others on the same medium with added mycobactin or on LJ with longer incubation periods, and some grew in 7 99 culture flasks (with or without mycobactin J). We did not obtain any growth of such strains on HEY, but not all samples were used to inoculate HEY slants. The single $C$ type strain isolated from sheep dates from 1993 and was cultured only on LJ. Consequently, our study does not indicate whether $C$ strains can be readily isolated from ovine samples on HEY, but other authors report that this is feasible $[7,15]$. Choy et al. $[23]$ reported that it would appear that the IS900-RFLP type is not correlated with the ability to culture isolates, as uncultivable sheep isolates from intestinal-mucosal homogenates in Australia had the same pattern $(S 1)$ as those from New Zealand grown on HEY [7]. Other factors, including mycobacterial concentration, contamination of inocula, susceptibility to hexadecylpyridinium-chloride (or other decontaminants) and/or different phenotypic stages could also contribute to the difficulty of culturing these strains. Only $26 \%$ of the Spanish goats analyzed were infected with strains belonging to the $C$ type: the other $74 \%$ had sheep $(S)$ type paratuberculosis. The cultural characteristics of caprine isolates depended on the strain type: $C$ strains had bovine-like characteristics and $S$ strains had ovine-like characteristics. This strain type distribution in goats disagrees with the findings of other authors in Spain and other countries $[12,17,35]$ who report a very low incidence of $S$ strains. The proportion of $S$ type isolates previously calculated [28] for Spanish goats (24.7\% of goat isolates and 39.1\% of flocks studied) is lower than that detected in our study (73.7\% of animals and $81.8 \%$ of flocks). These differences may be due to a culture media bias, but epidemiological 


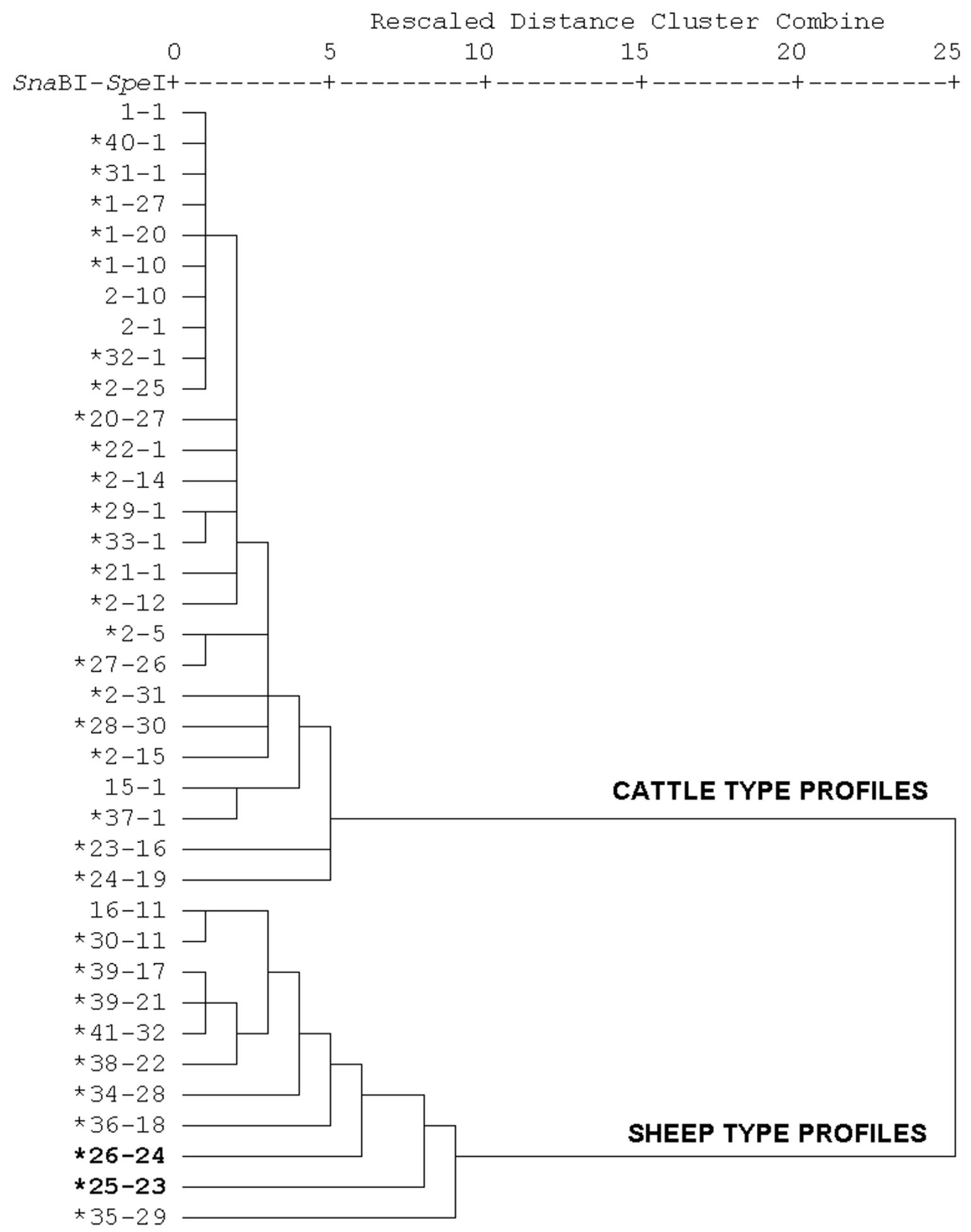

Figure 3

Dendrogram showing the similarities between multiplex PFGE profiles of isolates in the collection studied. The agglomerative hierarchical cluster analysis of the data using the unweighted pair group method with arithmetic averages divided strain profiles in two main branches, cattle type profiles and sheep type profiles. Profiles in boldface correspond to pigmented isolates. *novel profiles found in this study. 
Table 3: Distribution of Map genotypes among the different breeds of host species.

\begin{tabular}{|c|c|c|c|c|c|c|c|c|c|c|}
\hline \multirow[b]{2}{*}{ Breed } & \multicolumn{4}{|c|}{ CATTLE (232 isolates \& 228 animals) } & \multicolumn{3}{|c|}{ SHEEP ( 17 isolates \& 17 animals) } & \multicolumn{3}{|c|}{ GOAT (7 isolates \& 6 animals) } \\
\hline & Holstein & Limousin & Pyrenean & Bullfight & Latxa & Rasa-Aragonesa & Carranzana & Payoya & $\begin{array}{l}\text { Murciano- } \\
\text { Granadina }\end{array}$ & Saanen \\
\hline Isolates & $197(84.91)$ & $23(9.91)$ & $7(3.02)$ & $5(2.16)$ & $14(82.35)$ & $2(11.76)$ & I (5.89) & $3(42.86)$ & $3(42.86)$ & I (14.29) \\
\hline Animals & $193(84.65)$ & $23(10.09)$ & $7(3.07)$ & $5(2.19)$ & $14(82.35)$ & $2(11.76)$ & I (5.89) & $3(50.0)$ & $2(33.33)$ & I (16.67) \\
\hline Herds/Flocks & $100(76.34)$ & $22(16.79)$ & $6(4.58)$ & $3(2.29)$ & $7(70.0)$ & $2(20.0)$ & $\mathrm{I}(10.0)$ & $2(40.0)$ & $2(40.0)$ & I $(20.0)$ \\
\hline$I-I / C$ & $68(34.52)$ & $3(13.04)$ & $4(57.14)$ & & & & & & & \\
\hline $1-10 / C$ & & & I (14.29) & & & & & & & \\
\hline $\mathrm{I}-20 / \mathrm{C}$ & $\mathrm{I}(0.5 \mathrm{I})$ & & & & & & & & & \\
\hline $\mathrm{I}-27 / \mathrm{C}$ & $3(1.52)$ & & & & & & & & & \\
\hline $2-I / C$ & $103(52.28)$ & $15(65.22)$ & $2(28.57)$ & I (20.0) & & I (50.0) & & & $2(66.67)$ & \\
\hline $2-5 / C$ & $\mathrm{I}(0.5 \mathrm{I})$ & & & & & & & & & \\
\hline $2-10 / C$ & $\mathrm{I}(0.5 \mathrm{I})$ & & & $2(40.0)$ & & & & & & \\
\hline $2-12 / C$ & $\mathrm{I}(0.5 \mathrm{I})$ & & & & & & & & & \\
\hline $2-14 / C$ & $\mathrm{I}(0.5 \mathrm{I})$ & & & & & & & & & \\
\hline $2-15 / C$ & $3(1.52)$ & & & & & & & & & \\
\hline $2-25 / C$ & & & & $2(40.0)$ & & & & & & \\
\hline $2-31 / C$ & I (0.5 I) & & & & & & & & & \\
\hline $15-1 / C$ & & & & & & & & I (33.33) & & \\
\hline $20-27 / C$ & & $2(8.70)$ & & & & & & & & \\
\hline $21-1 / C$ & $\mathrm{I}(0.5 \mathrm{I})$ & & & & & & & & & \\
\hline $22-1 / C$ & $\mathrm{I}(0.5 \mathrm{I})$ & & & & & & & & & \\
\hline $23-16 / C$ & $6(3.05)$ & I (4.35) & & & & & & & & \\
\hline $24-19 / C$ & & I (4.35) & & & & & & & & \\
\hline $27-26 / C$ & I (0.5 I) & & & & & & & & & \\
\hline $28-30 / C$ & $\mathrm{I}(0.5 \mathrm{I})$ & & & & & & & & & \\
\hline $31-1 / C$ & $\mathrm{I}(0.5 \mathrm{I})$ & & & & & & & & & \\
\hline $32-1 / C$ & $2(1.02)$ & & & & & & & & & \\
\hline $33-1 / C$ & & I (4.35) & & & & & & & & \\
\hline $40-1 / C$ & $\mathrm{I}(0.5 \mathrm{I})$ & & & & & & & & & \\
\hline $16-11 / 5$ & & & & & & & & I (33.33) & I (33.33) & I (100.0) \\
\hline $25-23 / 5$ & & & & & & I (50.0) & & & & \\
\hline $26-24 / S$ & & & & & $3(2 \mid .43)$ & & & & & \\
\hline $30-11 / 5$ & & & & & $2(14.29)$ & & & & & \\
\hline $34-28 / 5$ & & & & & & & & I (33.33) & & \\
\hline $35-29 / 5$ & & & & & & & I (100.0) & & & \\
\hline $36-18 / 5$ & & & & & I (7.14) & & & & & \\
\hline $38-22 / 5$ & & & & & I (7.14) & & & & & \\
\hline $39-17 / 5$ & & & & & $4(28.57)$ & & & & & \\
\hline $39-21 / 5$ & & & & & $2(14.29)$ & & & & & \\
\hline $4 \mid-32 / 5$ & & & & & I (7.14) & & & & & \\
\hline
\end{tabular}

Number of isolates, animals and farms in Spain giving isolates of each SnaBI-Spel multiplex profile/ISI3II type according to the host species breed. Percentages are in brackets. 
reasons can not be ruled out. We found several goat flocks infected with both $C$ and $S$ types, although this was not the case for all farms or animal species studied. Our findings suggest that goats are highly susceptible to $C, S$ and $B$ Map strains.

Although we describe numerous multiplex PFGE profiles, nearly the $85 \%$ of bovine isolates belonged to only two different profiles, 1-1 and 2-1. The homogeneity of paratuberculosis isolates, especially bovine isolates, has been described before [10-12,19,38,43]. Apparently, particular Map strains have developed the ability to infect a wide range of types of cattle, and international trading has favored the worldwide spread of these strains. This may be accentuated by the genetic homogeneity of cattle as a result of genetic improvement programs and international trading. Indeed, bovine genotypes highly susceptible to certain strains may have spread across the world, and consequently the contact between other host species and these strains would have increased proportionally. We noted slight but interesting differences between strain types found in different bovine breeds coming from the same geographic area. Holstein cattle had the largest number of different profiles $(n=18)$, but this is unsurprising because it was the most numerous breed. More remarkable is the absence from Holsteins of 5 profiles detected in other breeds. Limousine cattle carried more 21 type and less 1-1 type than Holstein cattle. In contrast, the 1-1 strain was much more prevalent in Pyrenean cows. Cattle destined to bullfighting came from a less represented geographic area. With the exception of one 2-1 type, strains isolated from these animals $(n=5)$ showed rare profiles, suggesting a separate epidemiological context. This is in agreement with the results of the study by de Juan et al. [28] reporting a high proportion of Type I/ III isolates in two bullfighting cattle farms. Type 2-10 detected in 2 bullfighting and 1 Holstein animal, has only previously been reported in one goat from Norway [35]. The novel profile 2-25 was only isolated from two bullfighting animals. The differences of geographic origin of isolates may contribute to the differences found between cattle breeds, especially in bullfighting cattle.

The seven farms affected with 23-16 strains, are all in the same geographic area, some being only $30 \mathrm{~km}$ apart, and 5 of them also share the same veterinarian. These strains were isolated over several years (2000-2003) indicating persistence in this ecosystem. According to the phylogenetic analysis, this is one of the strains more different from the others in the bovine type sub-cluster. We are investigating probable links in food and water resources or historic introduction.

Ours is not the first description of mixed infection evidenced by isolation of different strains from the same ani- mal $[11,15,19]$, and could be similar to Mycobacterium avium polyclonal infections in human patients [44]. The bull with 3 different strains belonged to a Holstein herd with clinical paratuberculosis cases. The other two isolates obtained from the herd were typed as 1-1 and 2-1. This is consistent with types found in the bull, except for the extra profile (28-30) which was not isolated in any other animal. Re-infection of the animal by different strain types is the most probable explanation, because they were isolated from different biological samples and on different sampling dates.

Strain diversity in the sheep population was high. All the PFGE patterns of Spanish sheep isolates were different from those found in cattle, except for one 2-1 strain from a Rasa-Aragonesa sheep from Aragon. Pigmented isolates exhibited novel restriction patterns designated 26-24 and 25-23. The first was found in Latxa flocks in Basque Country and Navarra. These were not related to the RasaAragonesa sheep from Aragon infected with the other pigmented profile. This is the first report of pigmented strains in Spain. Pigmented strains were less prevalent than the 39-17 strain, found in Basque Country and Navarra. Three flocks in neighboring locations in the main area of prevalence in sheep in Basque Country, gave 3 isolates per flock. For each of the 3 flocks all 3 isolates differed from each other, but 39-17 type was found in all of them.

The diversity index calculated for goats was low. However, including goat isolates reported by de Juan et al. [35], the index is 0.817 . All isolates we cultured from goats, except one (34-28), have profiles that have previously been reported in this host species. The 16-11 type was observed throughout Spain and in numerous goat breeds. We detected the 15-1 type in goats in Cordoba (Andalucia), and it is also detected in other breeds in Madrid. In conclusion, goats in Spain are affected with a wide range of different strains, including $C$ and $S$ type strains.

Deer isolates had a novel profile (37-1) closely related to the 15-1 type (see Figure 3), previously found in the same area. Wild boar has carrion-eating behavior, and is a possible reservoir or vector of Map, which has been isolated several times from this species $[21,45,46]$. However, there is no evidence of diseased animals. The strain we isolated from wild boar was 2-1 type, a strain type that is widely disseminated. Cultures from India and bison isolates from USA showed different multiplex profiles, indicating they are different strains.

The phylogenetic dendrogram we constructed for our collection of paratuberculosis strains shows two distinct branches. One comprises isolates from cattle sheep, goats, deer, wild boar, and bison, whereas the other includes isolates only found in sheep and goats. This is in general 
agreement with previous work $[34,35]$. Our first branch (isolates from cattle and other hosts) is the same as the previously described Type II cluster, and IS900-RFLP Cattle types. The pigmented isolates from Scotland and Faroe Islands were included in the Type I cluster. However, type 16-11 found later in Spanish goats, was not included in Type I, and they were considered to be Type III. Our pigmented strain profiles clustered together with 16-11 strains and other isolates only found in sheep and goats. It is not clear where these novel profiles should be incorporated, but apparently they are more closely related to the 16-11 profile than to those previously described for pigmented isolates. Other studies included both Sheep and Intermediate IS900-RFLP types within the same cluster, composed of two different sub-clusters $[11,16]$. This seems to be a more accurate approach because Type III strains are very much closer to Type I than to Type II strains. Our findings confirm the soundness of the classification proposed by de Juan et al. [28] into 2 major types (Type I/III and Type II). These results suggest, however, that the original classification into cattle $(C)$ and sheep $(S)$ strains is more descriptive, has historic priority, and is substantially confirmed by the associations between bacterial type and host species (Figure 4). It is also consistent with the widely accepted practice in bacteriology of using as species name the Latin name of the species in which the parasite is found. Consequently, we strongly encourage the use of this system with only two groups corresponding to cattle and sheep.

The overall discriminatory power for this PFGE typing was not high but acceptable (0.693). The problem with this

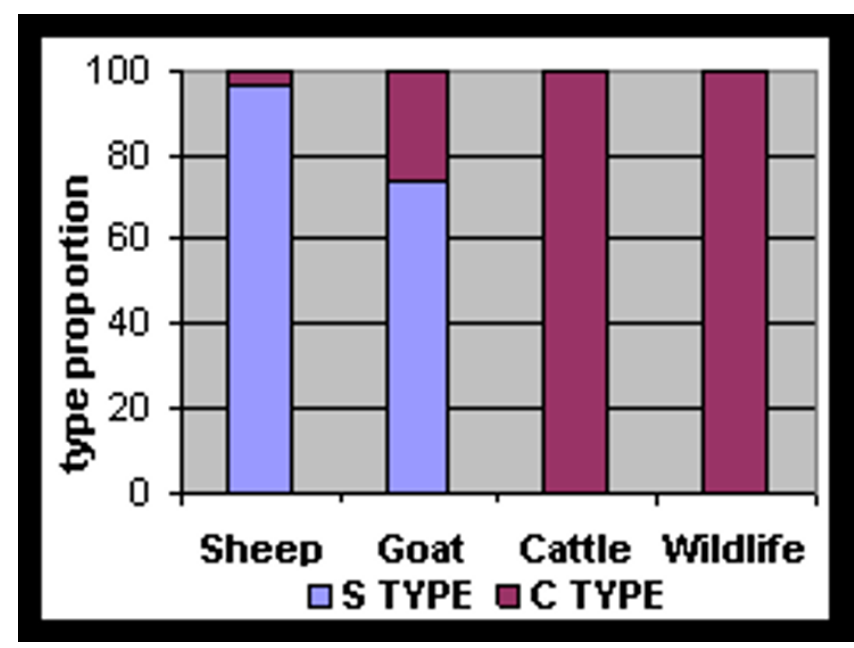

Figure 4

Strain type polarization in host species. Graphic representation showing the clear polarization of $C$ and $S$ strain types found in Spanish bovine, ovine, caprine and "wild" species. method appears to be the low degree of diversity of the bovine isolates rather than a true lack of power of the typing technique. Multiplex PFGE seems to be one of the most robust and reliable typing methods, because it explores the entire genome and only depends on the specificity of restriction endonucleases used. Other approaches depend on the distribution of repetitive DNA fragments, random amplification of certain fragments or on sequencing of variable repetitive regions; all these approaches can suffer from problems of reproducibility or reliability. However, PFGE is expensive and time consuming, in addition to the problem of obtaining typeable cultures. This method was unable to distinguish the IS1311$B$ type found in bison (PFGE 2-1) from other IS1311-C strains. The discrimination between IS1311- $B$ and $C$ is important, because these $B$ strains (from both India and USA) share the phenotypic characteristic of preferring eggbased media without added pyruvate [27].

\section{Conclusion}

Improved liquid culture media (based on Middebrook $7 \mathrm{H} 9)$ seem to be appropriate for primary isolation, because they appear to provide the entire isolation requirement spectrum of all strains. Nevertheless, we recommend the use of various solid media to avoid biases in primary isolation, and subculture of liquid cultures (when used for primary isolation) onto solid media to obtain pure colonies. Alternatively, PCR-based differentiation of strain type before culture inoculation may help to decide the media to be used.

High homogeneity of isolates from cattle, and heterogeneity of those from sheep and goats have been detected. Overall typing may need to be improved and this could be done by including an additional endonuclease or complementary techniques. PCR-REA typing is a powerful technique because it can both confirm Map identity and provide clear microbiological and epidemiological information. Systematic use of the more sophisticated PFGE method does not seem to be of much more benefit: it provides genetic information which does not appear to be clearly related to phenotypic properties but rather to limited epidemiologic details.

\section{Methods}

\section{Sources and growth of isolates}

Feces and tissue samples from cattle, sheep and goats were collected for routine paratuberculosis confirmation and for research purposes between 2000 and 2005. Twelve samples from sheep and one from a goat date from 19841999, and isolates obtained from these samples were maintained as glycerol stocks at $-80^{\circ} \mathrm{C}$. Most strains were from animals in northern regions of Spain, but strains from other Spanish regions were also included (see Figure 5). Four-hundred and forty-four paratuberculosis isolates 
were recovered from cattle ( $\mathrm{n}=409 ; 178$ herds), 27 from sheep ( $\mathrm{n}=27 ; 15$ flocks) and 21 from goats $(\mathrm{n}=19 ; 11$ flocks). Four of the ovine isolates were yellow pigmented (Figure 6). Map was also cultured from one deer (2 isolates from 2 different tissue samples) and one wild boar. Eight bovine cultures from Argentina, one from France and 3 ovine cultures from Portugal were also included, as well as isolates from American bison $(n=3)$ and Indian sheep $(n=2)$ and goats $(n=8)$. Samples were processed for culture of Map as described elsewhere [2]. Bovine samples were cultured on Herrold's egg yolk medium supplemented with mycobactin $\mathrm{J}(2 \mathrm{mg} / \mathrm{l}$ in all media containing the mycobactin) (Allied Monitor, Inc., Fayette, MO, USA) and sodium pyruvate (HEY). To avoid any bias in the recovery of strains from cattle, additional tubes of mycobactin J-supplemented Lowënstein-Jensen medium (LJ) were inoculated with bovine samples collected after 2002. Some bovine samples were also used to inoculate Middlebrook 7H11 supplemented with 1\% Middlebrook OADC Enrichment (Becton, Dickinson and Company, MD, USA) (7H11) and mycobactin J. Ovine and caprine samples were cultured on HEY, on LJ and/or on 7H11 (alternatively with mycobactin J), depending on when they were collected. Some of these cultures failed in the first attempt, and material stored at $-20^{\circ} \mathrm{C}$ was subsequently cultured again on Middlebrook $7 \mathrm{H} 9$ broth supplemented with OADC, 0.05\% Tween 80 (Panreac Quimica SA, Barcelona, Spain) (7H9) with or without added mycobactin J, and then sub-cultured on 7H11. Indian samples were initially grown on HEY without added pyruvate and bison samples on LJ. Deer samples were cultured on HEY and LJ, and wild boar samples on these two media and on 7H11 with mycobactin J.

\section{Cultures for PFGE}

High quality DNA could not be prepared from all samples due to loss of viability of some of the older isolates. Sufficient growth was obtained for PFGE typing with 232 isolates from cattle ( $\mathrm{n}=228 ; 131$ herds), 17 isolates from sheep ( $n=17 ; 10$ flocks), seven isolates from goats $(n=6$; 5 flocks), two from deer, one from wild boar, three from American bison and seven from Indian small ruminants (two from sheep and five from goats). Nearly 85\% of the bovine isolates were from Holstein (dairy) cattle, 10\% from Limousin (beef) cows, 3\% from Pyrenean (beef) cows, and $2 \%$ from Lidia (bullfighting) cattle. Spanish sheep were Latxa (dairy; $\mathrm{n}=14$ ), Rasa-Aragonesa (meat; $\mathrm{n}$ = 2) and Carranzana (dairy; $\mathrm{n}=1$ ). Goat breeds were Payoya (dairy/meat; $\mathrm{n}=3$ ), Murciano-Granadina (dairy/ meat; $\mathrm{n}=3$ ) and Saanen (dairy; $\mathrm{n}=1$ ). The Indian sheep (Muzzafarnagari) and goats (Barbari) were all meat breeds.

\section{Isolate identification: IS900 PCR and Locus 25 I PCR}

Map was identified on the basis of time of incubation to visible colonies, colony and bacillus morphology includ-

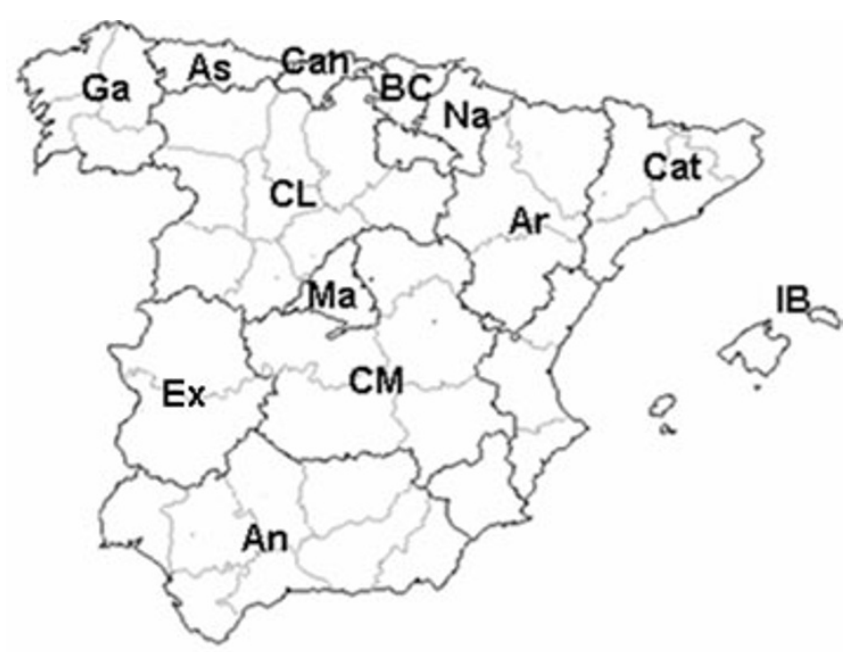

\section{Figure 5}

Map of Spain. Regions mentioned in the study are indicated as follows: $A n=$ Andalucia; $A r=$ Aragón; $A s=$ Asturias; $B C=$ Basque Country; Can = Cantabria; Cat = Cataluña; $C L=$ Castilla y León; CM = Castilla-La Mancha; Ex = Extremadura; $\mathrm{Ga}=$ Galicia; IB = Balearic Islands; $\mathrm{Ma}=$ Madrid; $\mathrm{Na}=\mathrm{Nav}-$ arra.

ing acid fastness, and mycobactin dependence on eggbased media. Isolates were screened for the presence of IS900 and Locus 251 [47] as follows. The method described by Garrido et al. [48] was used to extract DNA from single colonies or if there was no visible growth on solid media from broth culture pellets obtained by centrifugation of $5 \mathrm{ml}$ at $2000 \times \mathrm{g}$ for $15 \mathrm{~min}$. A GeneAmp 9600 PCR system (Applied Biosystems, Foster City, CA, USA) with specific primers were used for amplification under standardized conditions as described previously $[47,48]$. PCR products were subjected to electrophoresis in $2 \%(\mathrm{w} /$ v) agarose gels and stained with ethidium bromide to reveal DNA bands.

\section{ISI 3 I I PCR-REA}

A segment of IS1311 element was amplified and digested with HinfI and MseI (MseI only to rule out presence of Mycobacterium avium subsp. avium) endonucleases as described by Marsh et al. [25]. DNA fragments were separated by electrophoresis in $4 \%(\mathrm{w} / \mathrm{v})$ agarose gels stained with ethidium bromide. Isolates were classified as cattle $(C)$, sheep $(S)$ or bison (B) Map types according to previously published criteria $[25,49]$.

\section{SnaBI-Spel PFGE analysis}

A protocol described previously [34] was used to prepare mycobacterial DNA. Ten $\mathrm{ml}$ of $7 \mathrm{H} 9$ broth was inoculated and incubated at $37^{\circ} \mathrm{C}$ in a static $25 \mathrm{~cm}^{3}$ cell culture flask (Corning Inc., Corning, NY, USA). When sufficient growth was observed at the bottom of the flask, the cul- 


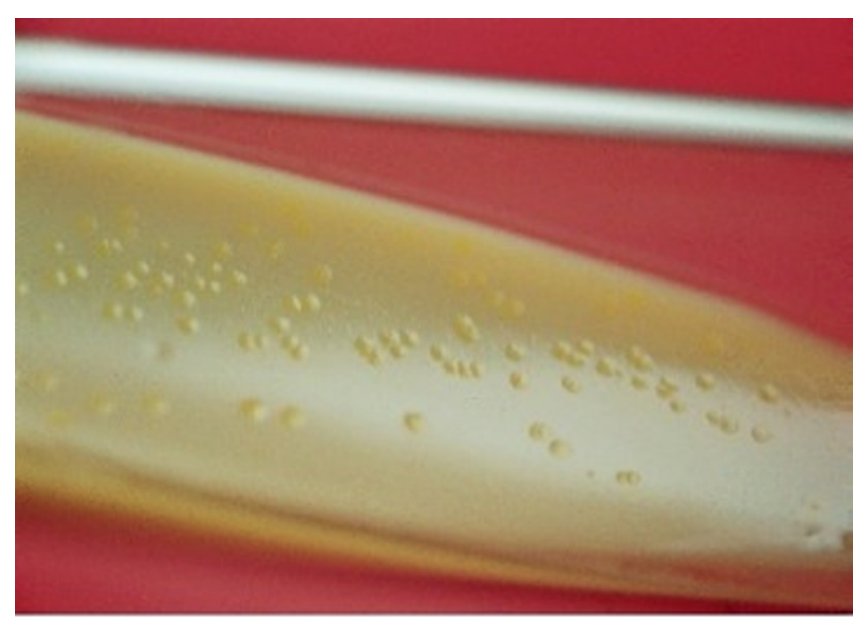

Figure 6

Pigmented ovine isolate. Pigmented colonies of Mycobacterium avium subsp. paratuberculosis on a Lowënstein-Jensen slant, isolated from the yellow-colored intestines of one sheep with clinical paratuberculosis from the Basque Country (Spain).

ture was homogenized by vigorous shaking and the optical density measured using a Densimat (Bio-Mérieux, Marcy L'Etoile, France). An appropriate volume of culture was centrifuged at $2000 \times \mathrm{g}$ for $15 \mathrm{~min}$, and the pellet washed and resuspended in modified spheroplasting buffer to obtain a bacterial suspension of approximately 6 $\times 10^{9}$ bacteria $/ \mathrm{ml}$. This suspension was heated to $55^{\circ} \mathrm{C}$ and mixed with an equal volume of molten $1.5 \%(\mathrm{w} / \mathrm{v})$ low-melting-point agarose (Biorad, Hemel Hempstead, Hertfordshire, United Kingdom) in 50 mM EDTA, then poured into plug molds (Biorad), and allowed to solidify at $4^{\circ} \mathrm{C}$. The plugs were incubated in a Tris-EDTA $(10 \mathrm{mM}$ Tris- $\mathrm{HCl}$ and $1 \mathrm{mM}$ EDTA; $\mathrm{pH} 8$ ) lysis solution containing $1.5 \mathrm{mg} / \mathrm{ml}$ lysozyme at $37^{\circ} \mathrm{C}$ for $16-20 \mathrm{~h}$. They were then placed with ESP solution (0.5 M EDTA, $1 \%$ (w/v) lauryl sarcosine and $1.5 \mathrm{mg} / \mathrm{ml}$ proteinase $\mathrm{K}$ ) and incubated at $55^{\circ} \mathrm{C}$ for at least 3 days. The ESP solution was discarded and the agarose plugs were washed in $\mathrm{pH} 8$ Tris-EDTA 6 times for $20 \mathrm{~min}$ each. The plugs were equilibrated in the restriction buffer supplied by the enzyme manufacturer ( 1 $\times \mathrm{NE}$ buffer and $0.1 \mathrm{mg} / \mathrm{ml}$ bovine serum albumin; New England Biolabs, Inc., Beverly, MA, USA) and then subjected to digestion with $20 \mathrm{U}$ of the appropriate endonuclease in fresh buffer at $37^{\circ} \mathrm{C}$ (SnaBI, $3 \mathrm{~h}$; SpeI, overnight). The plugs were placed in $\mathrm{pH} 8$ Tris-EDTA and loaded into a $1 \%(\mathrm{w} / \mathrm{v})$ pulsed field certified agarose gel (Biorad). Lambda midrange II PFG markers (New England Biolabs) and the type strain ATCC 19698 were included in every gel. Electrophoresis was carried out in a CHEF-DRII apparatus (BioRad). SnaBI restricted DNA was separated with initial and final switches of 6.8 and 26.3, respectively, and for separation of SpeI digests the values were 2.2 and 35.4, respectively. The electrophoresis time for SnaBI was $28 \mathrm{~h}$ to allow rapid screening of isolates, and samples with different and/or doubtful patterns were then electrophoresed for $40 \mathrm{~h}$ under the same conditions. Electrophoresis for SpeI gels was for $23 \mathrm{~h}$. The gradient applied was always 6 $\mathrm{V} / \mathrm{cm}$. DNA bands were visualized and photographed in a Fluor-S Multilmager (BioRad) after ethidium bromide staining. Nomenclature of novel patterns was as recommended elsewhere [34,35]. The first number refers to the SnaBI profile and the second to the SpeI profile, giving consecutive numbers to new profiles. Both molecular size markers and ATCC 19698 SnaBI and SpeI profiles were used as between-gel references for band identification.

\section{Phylogenetic analysis of PFGE profiles and estimation of genetic diversity}

PFGE images were analyzed with the Quantity One Software package version 4.5 (BioRad). Similarities between different multiplex profiles were calculated as Jaccard coefficients on the basis of band presence/absence scores with the SPSS software for Windows version 11.0 (SPSS Inc., Chicago, IL, USA). An agglomerative hierarchical cluster analysis of the data using the unweighted pair group method with arithmetic averages was used to construct a dendrogram. Simpson's Index of Diversity was calculated as follows to compare the genetic diversity of the isolates between host species and to asses the discriminatory power of the SnaBI-SpeI-PFGE typing: $1-[\Sigma$ (no. of isolates with a particular multiplex profile/total no. of isolates) $\left.{ }^{2}\right]$

\section{Authors' contributions}

IS carried out the laboratory and field work, compiled and analysed information and data, and drafted the manuscript as part of his PhD dissertation. JMG participated in the laboratory and field work, compiled information, coordinated the study and helped to draft the manuscript. MG participated in the laboratory and field work. RAJ conceived of and coordinated the study, and helped to draft the manuscript. All authors read and approved the final manuscript.

\section{Acknowledgements}

We wish to thank the farmers and veterinarians who provided the samples used in this study. J.M. Plazaola from the Diputación Foral of Gipuzkoa is acknowledged for his help with data collection. Numerous samples from Castilla-León were provided by the Pathology Unit, Faculty of Veterinary Medicine of the University of León (Spain) headed by V. Pérez and J.F.

García-Marín. Samples from wild boar and deer were sent by the Instituto de Investigación en Recursos Cinegéticos (IREC) in Ciudad Real (Spain) headed by C. Gortazar. Samples and cultures from Andalucía (Spain), Argentina, India, Portugal and USA were kindly provided by S. Rodríguez, A. Verna, S.V. Singh, A.C. Coelho and R. Whitlock, respectively. We are grateful to $G$. Aduriz for isolation and information on some strains. We also thank A. Badiola, Z. Pérez, I. del Pozo, M. Bascones, J.C. Ibabe and O. Aurtenetxe for their technical assistance. The work of I. Sevilla was supported by two research fellowships from the Department of Agriculture and Fish- 
eries, the Department of Industry and the Department of Education, Universities and Research of the Basque Government. This study was partially supported with EU-FEDER funds.

\section{References}

I. Kennedy DJ, Benedictus G: Control of Mycobacterium avium subsp. paratuberculosis infection in agricultural species. Rev - Off Int Epizoot 200I, 20:15I-179.

2. Aduriz JJ, Juste RA, Cortabarría N: Lack of mycobactin dependence of mycobacteria isolated on Middlebrook 7HI I from clinical cases of ovine paratuberculosis. Vet Microbiol 1995 45:2II-2I7.

3. Motiwala AS, Amonsin A, Strother M, Manning El, Kapur V, Sreevatsan S: Molecular epidemiology of Mycobacterium avium subsp. paratuberculosis isolates recovered from wild animal species. I Clin Microbiol 2004, 42: I703-I7I2

4. Cousins DV, Whittington R, Marsh I, Masters A, Evans RJ, Kluver P Mycobacteria distinct from Mycobacterium avium subsp. paratuberculosis isolated from the faeces of ruminants posses IS900-like sequences detectable by IS900 polymerase chain reaction: implications for the diagnosis. Mol Cell Probes 1999, 1 3:431-442.

5. Englund S, Bolske G, Johansson KE: An IS900-like sequence found in a Mycobacterium sp. other than Mycobacterium avium subsp. paratuberculosis. FEMS Microbiol Lett 2002, 209:267-27I

6. Naser SA, Felix J, Liping H, Romero C, Naser N, Walsh A, Safranek W: Occurrence of the IS900 gene in Mycobacterium avium complex derived from HIV patients. Mol Cell Probes 1999 | 3:367-372

7. Collins DM, Gabric DM, de Lisle GW: Identification of two groups of Mycobacterium paratuberculosis strains by restriction analysis and DNA hybridization. I Clin Microbiol 1990, 28:159|-1596.

8. Stamp JT, Watt JA: Johne's disease in sheep. J Comp Pathol 1954, 64:26-38.

9. Whittington RJ, Marsh I, McAllister S, Turner MJ, Marshall DJ, Fraser CA: Evaluation of modified BACTECI2B radiometric medium and solid media for culture of Mycobacterium avium subsp. paratuberculosis from sheep. J Clin Microbiol 1999, 37:1077-1083.

10. Bauerfeind R, Benazzi S, Weiss R, Schliesser T, Willems H, Baljer G: Molecular characterization of Mycobacterium paratuberculosis isolates from sheep, goats and cattle by hybridization with a DNA probe to insertion element IS900. J Clin Microbio 1996, 34:1617-1621.

II. Cousins DV, Williams SN, Hope A, Eamens G]: DNA fingerprint ing of Australian isolates of Mycobacterium avium subsp. paratuberculosis using IS900 RFLP. Aust Vet / 2000, 78: 184-190.

12. Dionne B, Pavlik I, Svastova P, Bartos M, Holstad G: IS900 restric tion fragment length polymorphism (RFLP) analysis of Mycobacterium avium subsp. paratuberculosis isolates from goats and cattle in Norway. Acta Vet Scand 2005, 46: I3-I8.

13. Greig A, Stevenson K, Henderson D, Perez V, Hughes V, Pavlik I, Hines ME, McKendrick I, Sharp JM: Epidemiological study of paratuberculosis in wild rabbits in Scotland. I Clin Microbio |999, 37:|746-|75|

14. Moreira AR, Paolicchi F, Morsella C, Zumarraga M, Cataldi A, Fabiana B, Alicia A, Piet O, van Soolingen D, Isabel RM: Distribution of IS900 restriction fragment polymorphism types among animal Mycobacterium avium subsp. pratuberculosis isolates from Argentina and Europe. Vet Microbiol 1999, 70:251-259.

I5. Pavlik I, Pavlas BM, Kosková RS: Characterization by restriction endonuclease analysis and DNA hybridization using IS900 of bovine, ovine, caprine and human dependent strains of Mycobacterium paratuberculosis isolated in various localities. Vet Microbiol 1995, 45:31 I-318.

16. Pavlik I, Horvathova A, Dvorska L, Bartl J, Svastova P, du Maine R Rychlik I: Standardisation of restriction fragment length polymorphism analysis for Mycobacterium avium subspecies paratuberculosis. J Microbiol Methods 1999, 38:155-167.

17. Thoresen OF, Olsaker I: Distribution and hybridization patterns of the insertion element IS900 in clinical isolates of Mycobacterium paratuberculosis. Vet Microbiol 1994 40:293-303.
18. Whipple D, Kapke P, Vary C: Identification of restriction fragment length polymorphisms in DNA from Mycobacterium paratuberculosis. J Clin Microbiol 1990, 28:256I-2564.

19. Whittington RJ, Hope AF, Marshall DJ, Taragel CA, Marsh I: Molecular epidemiology of Mycobacterium avium subsp. paratuberculosis: IS900 restriction fragment length polymorphism and ISI 3 I I polymorphism analyses of isolates from animals and a human in Australia. J Clin Microbiol 2000, 38:3240-3248.

20. de Lisle GW, Yates GF, Collins DM: Paratuberculosis in farmed deer: case reports and DNA characterization of isolates of Mycobacterium paratuberculosis. J Vet Diagn Invest 1993, 5:567-57I.

21. Machackova M, Svastova P, Lamka J, Parmova I, Liska V, Smolik J, Fischer OA, Pavlik I: Paratuberculosis in farmed and free-living wild ruminants in the Czech Republic (I999-200 I). Vet Microbiol 2004, I 0 I:225-234

22. Pavlik I, Bartl J, Dvorska L, Svastova P, du MR, Machackova M, Yayo AW, Horvathova A: Epidemiology of paratuberculosis in wild ruminants studied by restriction fragment length polymorphism in the Czech Republic during the period 1995-1998. Vet Microbiol 2000, 77:23I-25I.

23. Choy E, Whittington RJ, Marsh I, Marshall J, Campbell MT: A method for purification and characterization of Mycobacterium avium subsp. paratuberculosis from the intestinal mucosa of sheep with Johne's daisease. Vet Microbiol 1998, 64:5I-60.

24. de Lisle GW, Collins DM, Huchzermeyer HFAK: Characterization of ovine strains of Mycobacterium paratuberculosis by restriction endonuclease analysis and DNA hybridization. Onderstepoort J Vet Res 1992, 59: 163-165.

25. Marsh I, Whittington R, Cousins D: PCR-restriction endonuclease analysis for identification and strain typing of Mycobacterium avium subsp. paratuberculosis and Mycobacterium avium subsp. avium based on polymorphisms in ISI 3 II. Mol Cell Probes 1999, I3:II5-126.

26. Whittington RJ, Taragel CA, Ottaway S, Marsh I, Seaman J, Fridriksdottir V: Molecular epidemiological confirmation and circumstances of occurrence of sheep (S) strains of Mycobacterium avium subsp. paratuberculosis in cases of paratuberculosis in cattle in Australia and sheep and cattle in Iceland. Vet Microbiol 2001, 79:3 I I-322.

27. Sevilla I, Singh SV, Garrido JM, Aduriz G, Rodríguez S, Geijo MV Whittington RJ, Saunders V, Whitlock RH, Juste RA: PCR-REA genotype of paratuberculosis strains isolated from different host species and geographic locations. Rev - Off Int Epizoot 2005, 24: $1061-1066$.

28. de Juan L, Alvarez J, Aranaz A, Rodriguez A, Romero B, Bezos J Mateos A, Dominguez L: Molecular epidemiology of Types I/III strains of Mycobacterium avium subspecies paratuberculosis isolated from goats and cattle. Vet Microbiol 2006, I I 5: I02-I I0.

29. Coffin JW, Condon C, Compston CA, Potter KN, Lamontagne LR, Shafiq J, Kunimoto DY: Use of restriction fragment length polymorphisms resolved by pulsed-field gel electrophoresis for subspecies identification of mycobacteria in the Mycobacterium avium complex and for isolation of DNA probes. J Clin Microbiol 1992, 30:1829-1836.

30. Feizabadi MM, Robertson ID, Cousins DV, Hampson DJ: Genomic analysis of Mycobacterium bovis and other members of the Mycobacterium tuberculosis complex by isoenzyme analysis and pulsed-field gel electrophoresis. J Clin Microbiol 1996, 34: I136-1142.

31. Kim JR, Kim $\mathrm{CH}$ : Genomic polymorphism in clinical mycobacterial strains analyzed by pulsed-field gel electrophoresis. J Microbiol 1997, 35: I72-I76.

32. Levy-Frebault VV, Thorel MF, Varnerot A, Gicquel B: DNA polymorphism in Mycobacterium paratuberculosis, "wood pigeon mycobacteria", and related mycobacteria analyzed by field inversion gel electrophoresis. J Clin Microbiol 1989, 27:2823-2826.

33. Singh SP, Salamon H, Lahti CJ, Farid-Moyer M, Small PM: Use of pulsed-field gel electrophoresis for molecular epidemiologic and population genetic studies of Mycobacterium tuberculosis. J Clin Microbiol 1999, 37:1927-1931.

34. Stevenson K, Hughes VM, de Juan L, Inglis NF, Wright F, Sharp JM: Molecular characterization of pigmented and nonpigmented 
isolates of Mycobacterium avium subsp. paratuberculosis. Clin Microbiol 2002, 40: I 798-I804.

35. de Juan L, Mateos A, Dominguez L, Sharp JM, Stevenson K: Genetic diversity of Mycobacterium avium subspecies paratuberculosis isolates from goats detected by pulsed-field gel electrophoresis. Vet Microbiol 2005, 106:249-257.

36. Amonsin A, Li LL, Zhang Q, Bannantine JP, Motiwala AS, Sreevatsan $S$, Kapur V: Multilocus short sequence repeat sequencing approach for differentiating among Mycobacterium avium subsp. paratuberculosis strains. J Clin Microbiol 2004, 42:1694-1702.

37. Bull TJ, Hermon-Taylor J, Pavlik I, El Zaatari F, Tizard M: Characterization of IS900 loci in Mycobacterium avium subsp. paratuberculosis and development of multiplex PCR typing. Microbiology 2000, I46:2185-2197.

38. Motiwala AS, Strother M, Amonsin A, Byrum B, Naser SA, Stabel JR, Shulaw WP, Bannantine JP, Kapur V, Sreevatsan S: Molecular epidemiology of Mycobacterium avium subsp. paratuberculosis: evidence for limited strain diversity, strain sharing, and identification of unique targets for diagnosis. J Clin Microbiol 2003 4I:2015-2026

39. Overduin P, Schouls L, Roholl P, van der ZA, Mahmmod N, Herrewegh A, van Soolingen $D$ : Use of multilocus variable-number tandem-repeat analysis for typing Mycobacterium avium subsp. paratuberculosis. J Clin Microbiol 2004, 42:5022-5028.

40. Pillai SR, Jayarao BM, Gummo JD, Hue EC, Tiwari D, Stabel JR, Whitlock RH: Identification and sub-typing of Mycobacterium avium subsp. paratuberculosis and Mycobacterium avium subsp. avium by randomly amplified polymorphic DNA. Vet Microbiol 200I, 79:275-284.

4I. Juste RA, Marco JC, Saez de Ocariz C, Aduriz J]: Comparison of different media for the isolation of small ruminant strains of Mycobacterium paratuberculosis. Vet Microbiol 1991, 28:385-390.

42. de Juan L, Alvarez J, Romero B, Bezos J, Castellanos E, Aranaz A, Mateos A, Dominguez $L$ : Comparison of four different culture media for isolation and growth of type II and type I/III Mycobacterium avium subsp. paratuberculosis strains isolated from cattle and goats. Appl Environ Microbiol 2006, 72:5927-5932

43. Feizabadi MM, Robertson ID, Hope A, Cousins DV, Hampson DJ: Differentiation of Australian isolates of Mycobacterium paratuberculosis using pulsed-field gel electrophoresis. Aust Vet $J$ 1997, 75:887-889.

44. Arbeit RD, Slutsky A, Barber TW, Maslow JN, Niemczyk S, Falkinham III JO, O'Connor GT, Von Reyn CF: Genetic diversity among strains of Mycobacterium avium causing monoclonal and polyclonal bacteremia in patients with AIDS. J Infect Dis 1993, 167:1384-1390.

45. Alvarez J, de Juan L, Briones V, Romero B, Aranaz A, FernandezGarayzabal JF, Mateos A: Mycobacterium avium subspecies paratuberculosis in fallow deer and wild boar in Spain. Vet Rec 2005, I 56:2/2-213.

46. Machackova M, Matlova L, Lamka J, Smolik J, Melicharek I, Hanzlikova M, Docekal J, Cretnic Z, Nagy G, Lipiec M, Ocepek M, Pavlik I: Wild boar (Sus scrofa) as a possible vector of mycobacterial infections: review of literature and critical analysis of data from Central Europe between 1983 to 200I. Vet Med (Praha) 2003, 48:5I-65.

47. Bannantine JP, Baechler E, Zhang Q, Li L, Kapur V: Genome scale comparison of Mycobacterium avium subsp. paratuberculosis with Mycobacterium avium subsp. avium reveals potential diagnostic sequences. J Clin Microbiol 2002, 40:1303-1310.

48. Garrido JM, Cortabarria N, Oguiza JA, Aduriz G, Juste RA: Use of a PCR method on fecal samples for diagnosis of sheep paratuberculosis. Vet Microbiol 2000, 77:379-386.

49. Whittington RJ, Marsh IB, Whitlock RH: Typing of IS I 3 II polymorphisms confirms that bison (Bison bison) with paratuberculosis in Montana are infected with a strain of Mycobacterium avium subsp. paratuberculosis distinct from that occurring in cattle and other domesticated livestock. Mol Cell Probes 200I, 15:139-145.

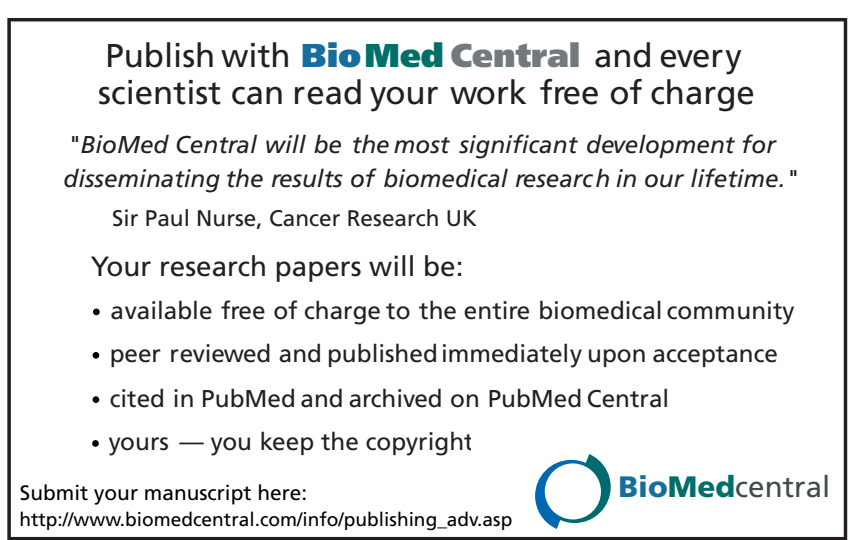

